\title{
My Viewpoint about Financial Management Education in Chinese Family
}

\author{
Mei Naxin \\ zhengzhou children normal specialised college \\ Zhengzhou,China, 450000 \\ e-mail: mnx24685@163.com
}

\begin{abstract}
The importance of family financial management education of primary and middle school students have been reviewed in China. This paper expounded the necessity and urgency of the financial management education and how to form an independent view of the consumer, financial management concept and my viewpoint about financial management education in chinese family.
\end{abstract}

Keywords- family education; financial management; primary and middle school students

\section{INTRODUCTION}

Financial management is the ability to manage the money and use the money properly. Financial management is not only a science, but also it is a life skill courses teach students how to survive in the future.Financial education and induction of primary and middle students, so they were trained to establish the concept of money and scientific way of managing money is very necessary. At present school education mainly exam-oriented education, a serious lack of financial education, then, the parents of children financial management aspects of culture can not be ignore. Parents teach their children financial management, is to extend the education chain students perceived social practice, know how to live, learn to survive exercise capacity, and thus, enhance the ability to adapt to society.

\section{THE IMPORTANCE OF FAMILY FINANCIAL EDUCATION}

Society requires a modern sound personality and sense of independence as well as to manage the basic quality of economic life. In taking economic construction as the center of times, financial management consciousness and ability is growing more and more importance. Some developed countries in the world from the child a child will improve the occasion to financial education. The financial education from an early age began in the United States. For just a self-care ability of children in the United States, parents never easy to give them pocket money .If children ask their parents for money, they need to write IOUs .Pocket money are earned through their own labor. The world software giant Microsoft corp. chairman Bill Gates was born in a wealthy Seattle lawyer family and his father, William paid great attention to the young a sense of on merit hard work. William said : 'It is important to let the child know that they can make money, and whether to do something must have confidence and drive' .Gates help do some homework, my father always give a little reward, in order to inspire his enthusiasm he knows how to work a step to happiness. William believes that doing so allows the child to understand the social reality and the outside world, so that children can also understand labor together and happy together $[1,2]$. So, in the United States, their children generally have a strong independence and economic awareness, management and operating capacity of economic affairs is also very strong, strong human resources base to cultivate a large number of excellent economic management.

Financial education also helps children to form good moral character. The children very easy to get money, it is difficult to make them feel the money need to rely on their own efforts to earn hard earned money of their parents , should pay attention to saving, rational consumption. For example, from the parents hands easily get pocket money, get some money during the Spring Festival, accepting birthday gifts etc, It is not beneficial to the formation of good character. Condone child irrational consumption or lack of guidance on children consumption. Children not only difficult to form a correct conception of personal finance and financial management capability, but also will form the vanity, hedonism, dependent adverse character. Financial education enables children to form thrifty, reasonable consumption, respect for parents, love of learning, love of labor and other good qualities.

At present,with the improvement of the social economic development level, plus most of the urban households in China have only one child, some parents in their children 's consumption issues, hold indulgent attitude , causing the child to be able to easily get money, they have pocket money, and even personal passbook .These parents in the consumer decision to children as the center to the child for money demand, just meet, responsive. Independent macro news consumption on their children, without guidance management, go with the flow, many children only know to spend money, do not manage money, spend money, there mindless consumption show off the consumer and high-end consumer misunderstanding parents think small children lack of experience, not consumer finance, on the line as long as the control of their learning. This kind of wrong consumption phenomenon will make the children formed many bad quality, all of these are critical to the child survival and development of the event, from the reality, the parents should strengthen financial education sense of urgency.

\section{MISUNDERSTANDING OF THE FAMILY FINANCIAL EDUCATION}

In the eyes of many adults, breadwinners and manage money has always been a thing of adults, children no decision-making power consumption, and no money to 
manage , there is no need for the children to know how to manage money, grow up, they will naturally ; some parents think that the breadwinner , rational planning consumer is more abstract topics , a child is not easy to understand this truth, rather than let these heavy topics understanding into the lives of children, it would be better to let them live happily, so they grew up, life experience is more experienced and will naturally understand the reason[3]. Because their parents think that family financial education to the child has no meaning, the child's learning and daily consumption, the lack of financial education guidance, so that children know only spend money, don't tube money; Some parents in the children consumer issues, the indulgence attitude. Children in to eat, wear, use, etc. hedonism, the pursuit of eat , drink , play, music , vanity , the comparisons in order to obtain self-esteem , the consequences to children covet material to enjoy, not endure hardship , spendthrift , dependence and independence, such as impact studies; some parents think that today society is the economic and social money society, with the money will have everything . Parents indulge their children consumption reason is complicated. Some parents for doting, love their children more than lack of education management, doting, will meet the child excessive, unreasonable consumer demand. Some parents of compensation psychology, youth suffer hardship , now living conditions are good, unwilling to let the children again suffer, even he can not be sure children. Some parents are out of the herd mentality and notice many children arbitrary in eating, wearing, using and playing and other , They worry their children bring about inferiority when dealing with them due to consumption of restricted inferiority complex, is not conducive to the child's gregarious, they think other children are so why must let their children were different. These are the most common misunderstanding of financial education.

Of course, some parents limit their children to independent consumer hands money to keep the kids , prohibit child independent macro news consumption , public consumption, regardless of family or child personal consumption, entirely by parents call the shots , implemented in the child life, not consumer autonomy. Due to the parents to their children a consumption control, even deprivation, children are less vulnerable to consumer finance education, there are few consumer finance practice opportunities, this not only make them in household spending on finance in a passive position, and easy to produce the inferiority mentality, which is unfavorable to their children a good moral character and consumer finance consciousness and ability of the form. Parents control their children consumption, deprive the children of financial reasons are varied. Some parents believe that learning is the sole responsibility of the child life, should not let the consumer financial impact a child's development. There are small children, lack of experience, not consumer finance, so that they do these things will make things screws. Some parents limit not clear, need to children do things arranged, instead of children instead of consumer finance. Words and deeds, such stereotypes affect modern awareness of children , family consumer financial aspects of the generation gap and thus affect the formation of child modern consumer financial concepts and the results will make the children form a traditional consumer financial concepts and thus make the child difficult to adapt to social development .

\section{MY OPINION OF THE FAMILY FINANCIAL EDUCATION}

In view of financial education the necessity, urgency, should be in the primary school is grade three open schoolbased curriculum "financial education", the cultivation of the students' consciousness of money at the same time, to develop their labor concept, teach children "labor create wealth" the truth, the teacher can give students homework, let them go to the library, bookstore refer to ancient and modern, Chinese and foreign successful story, with the power of images teach them the truth of the rich labor. Financial management is a kind of comprehensive ability, only combining theory with practice, let the students return to life, learn to reasonable consumption, financial management ability can obtain the exercise and the enhancement, financial education will into effect. Teacher can hand bank card, phone card, bus card, shopping card into the classroom , so that children understand the function of the card, the card convenience[4].School-based curriculum can use the teachers and students to interact, group learning, independent inquiry, comprehensive practice and other forms, and carry out wonderful novel financial education activities, can cultivate students' good financial habits.

Aiming at the curriculum system setting and takes an exam the education reality. Family education and financial education must be added[5]. I think according to the actual situation, to train the children the proper way of money. For preschool children, mainly parents led consumer, and to be guided, is recommended for middle school students, parents , in consultation with the child, give a fixed amount every week, so the child's own plan , their own disposable parental supervision. Additional, still be possible to study the mathematical knowledge, ideological and moral education of knowledge, used in real life. Such as, primary school grade five learned percent, can let the child calculation deposit interest, know annual rate and monthly interest rate difference, calculation welfare lottery winning probability. Middle school students can make their stock trading income calculation, and let them understand what is Consumer Price Index, Manufacturing Index, etc. Into life , through their own perception of concern the market price dynamics, life is a very vivid classroom, the children at any time you can see free gifts, tryout, discount coupons and recognize that free stuff must include other costs, let them remember that 'there is no free lunch'. About family financial education, the parents need to create opportunities for children to take the initiative to participate in some activities. As for the home under the guidance of their parents to buy food, pay the telephone charges, pay water and electricity, etc. Parents can also tell him how to spend the money to help children understand how in charge of the family finances and can strengthen children financial literacy and financial management practices, after a considerable period of time, 
can form an independent view of the consumer and the financial outlook.

Early adolescent younger age as financial investors, financial planning education gradually attracted people's attention. Visa International union Baxter Education Advisory Center and many other institutions jointly opened the first youth professional financial planning education website. Website content for young people (from 6 to 18 years old) is designed to promote the development of the financial education of the youth in the country. Through the site, young people can understand and learn a variety of financial literacy, participated in various financial management skills training activities. In the past ten years, Visa has continued to develop a variety of financial planning education and training courses to teach people how to engage in money management in a responsible manner, such as budgeting, management expenses and save money. Support financial planning education is not only helpful to Visa's business, it is a very useful cause to society. Visa financial planning education work carried out in the world for nearly two decades, various financial education activities have been deep into the past more than 30 countries and regions. Only in the past three years, Visa's financial planning education projects covered in the global number had more than 1200 people.

There are some social phenomenon in China,for example, Card slave, run out of money, rely on family. It reflects the young people in the financial management ability and the lack of consciousness. The study showed that the 6-12 year old is the golden age of children financial education, the emphasis on the financial ability of the ages of children, is also an important means to enhance the financial management capacity of the community as a whole. As a child's first teacher, the parents should be the emphasis on the financial education of the child's everyday life, with your children and children together to discuss the number of monthly pocket money, whether it is reasonable to analyze the use of pocket money for kids to participate in financial education activities can help kids establish a correct concept of financial management, improve children financial Business Index.

Recently,the good news is China youth research institute, China concerned about the next generation working committee public cultural center held the 2012 Chinese children wealth quotient index research and 'financial child star' selection activities, hoping to arouse the Chinese parents for primary and middle school students financial education attention.. With the increasing number of family and social wealth, the variety of financial instruments and products constantly, thrift and economy of this traditional conception of personal finance is given a richer connotation, early financial education of the children, help them to establish a correct concept of money, rational, moderate consumption concept, to develop good financial habits. Not only be able to solve practical problems children face in daily life and social activities on money and wealth, strengthening quality education, and can guide the kids to learn to plan dreams and management of life, which will become their lifetime wealth.

\section{REFERENCES}

[1] An Shiying Zhong Hua and Xu Liming. Two reflections on family financial education. Cultural and Educational Material 2006,pp.32 33.

[2] Qiao Xiaoli. Financial education in primary and middle schools abroad and Its implications. Teaching and Management: Primary School Edition. 2006,pp.79-80.

[3] Zeng Xiaoyan. Indispensable financial education. family education. 2006,pp.43-43.

[4] Wen Zhiwang. Practice of Pupils Fiscal education. teaching and management: Primary School Edition. 2012,pp.14-16.

[5] Liu Xiaojun. Three Big Stage of children's financial education. maternal and child world. 2012,pp.138-139. 